\title{
Publish and Protect
}

As recently as 6 or 7 years ago, a large number of the research workers in the field of biotechnology seemed to be just awakening to the realities of intellectual property and technology transfer, even though many of their colleagues in other research fields had long realized the situation. It was considered an act of mistrust to ask someone to sign a nondisclosure agreement before sharing novel research information and materials. The unrestricted exchange of information was considered the only way to ensure that progress was not inhibited by delay and the only way to overcome secrecy and greed. Attitudes have changed considerably, mainly for two reasons: first, the decision in 1980 of the USA Supreme Court to permit the patenting of biotechnology developments involving man-made microorganisms and second, the possible 'million-dollar' profit potential on the stock market for these same biotechnology developments. Nowadays, sharing information which may have potential commercial value under a confidentiality agreement is an accepted way of life. Such agreements generally specify the ownership of the material and restrict its usage to specific research purposes; they also quite often request that material received under such an agreement not be distributed to third parties without prior permission from the owner. Because of industry's increased financial interest in biotechnology, the patenting and licencing of research results in this area has increased. Even for those scientists who would still prefer to share freeely, the reality is that if their product is to be marketed, be it for the benefit of mankind, financial benefit or both, it must be protected to provide the incentives (through exclusive licenses) to commercial companies interested in marketing that product. There is scant commercial interest in spending large sums of money, sometimes tens of millions of US dollars, in the further development of a product if, in the end, that product cannot be marketed exclusively.

It is reasonable to assume that most research institutions today could well benefit from additional income, especially if it is generated from their own work. Therefore, it would be in their interest to protect research results with commercial potential in order to make available this additional income to themselves. This would equally apply to individual researchers benefiting directly from sharing in royalty income. The advantages

\section{Editorial}

would be the further development of their product, providing them with additional information and research material, the commercialization of this product and its availability to the public, and additional income to finance ongoing or new research projects. The disadvantages are the temporarily imposed restrictions on the distribution of information, the additional paper work required for the agreements and the filling of patent applications and, last but not least, the cost of filing such applications. In this age of almost instant communication, the possible delays in distribution of information can be reduced by using electronic mail or telefax instead of normal mail, etc. depending on the urgency of the situation.

The process of filing patent applications requires expert advice and the involvement of patent attorneys - this costs money. The patent application fee and other fees vary from country to 
country but the preparation and filing of an application in the USA, including the various searches, etc., may cost approximately US\$ 8,000.00, and when the cost of prosecuting the patent application to issuance is added, the total will undoubtedly exceed US\$12,000.00. It, therefore, becomes important to select very carefully those projects which warrant patenting. There are certainly different ways of evaluating such projects. One recommended way would be to utilize technology transfer specialists, a company or corporation, specifically organized and staffed to carry out the necessary evaluation and novelty searches to make rational and economically justified decisions.

The percentage of research projects resulting in patentable inventions is relatively small. However, many nonpatentable processes and techniques may be of commercial interest with some having the potential for income under so-called 'know-how' agreements. Here again, ongoing supervision and expert advice in the field are of extreme importance.

What exactly constitutes a disclosure and when are research results in the public domain and, therefore, no longer protected are critical issues. The answers to these questions are complex, mainly because patent law varies from country to country. There are, however, some basic ground rules.

First of all, research ideas and results should be routinely recorded in a bound laboratory notebook, dated, signed and witnessed. However odd this might sound, there are good reasons for these requirements. In certain countries, the date the idea occurred and the date it was put into practical form are critical. Once the concept or hypothesis has been formulated, it is necessary to prove it experimentally -just having the idea alone does not protect your priority to this invention.

Publishing before filing a patent application can jeopardize the right to obtain patent protection for research results. A researcher should be cognizant of the fact that in most countries of the world, publication before filing a patent application precludes patent protection. There are some notable exceptions: the USA has a 1-year grace period following publication in which one can still file a patent application. The grace period for Canada is 2 years and Japan, 6 months. 'Published' in terms of patent protection does not only refer to material printed and available to the public such as articles in newspapers or journals. It also includes theses and reports which have been catalogued and made available in a library accessible to the public. An oral presentation at a Editorial

public meeting in some countries qualifies as a publication, and if this presentation was reported by a journalist present at the meeting or circulated at the meeting in the form of an abstract, then it is definitely considered a publication. In general, there is one saving grace in all this; the publication must be 'enabling'. This means, it must describe the invention in such a way that someone familiar with the field could duplicate it or put it to use. It should be noted also that an enabling publication can be written by someone familiar with the invention - someone other than the inventor!

'Inventor' - the dictionary definition is 'he/she who creates by thought, originates (new method, instrument, etc.)'. Unfortunately, this definition for patent purposes does not hold true in all countries. Some countries define as the inventor the person who first thought of and implemented an idea. Other countries, however, define as the inventor the person who first files the invention. 
There are, therefore, three options to publish and protect:

The researcher who believes he has an invention worth protecting can write and talk about this invention in broad terms, carefully avoiding details that would qualify as an enabling publication.

He/she may decide to publish his/her discoveries in detail and file a local patent application within the time limit allowed under local law (in the USA this would be 1 year), but forfeiting patent protection in other countries.

(3) $\mathrm{He} /$ she may file for a provisional patent locally prior to publication, thus securing an early priority date and gaining time (in the USA 1 year) to consider the desirability of patent protection in other countries.

It is important that the first filed patent application, upon which priority may by based in other countries, contains an enabling disclosure of the invention in order to satisfy the requirements of countries such as the USA.

Here I would like to reemphasize - these are basic suggestions. The laws are so different from country to country that it is necessary to find out locally what regulations apply in your country. In conclusion, therefore, in the case of new human therapies and diagnostics, patent protection is a necessity to ensure their development to marketable products. Another consideration is that the patent owner can direct the development process to guarantee that the public benefits from his research. In addition, patents can provide the mechanism by which the profits from their commercialization are shared by the institution and the researcher.

M. Richner-Gilhuys

Ludwig Institute for Cancer Research

Stadelhoferstrasse 22

CH-8001 Zurich (Switzerland) 